\title{
Correction to: The Geography of Climate Change Adaptation in Urban Africa
}

\author{
Patrick Brandful Cobbinah and Michael Addaney
}

\section{Correction to:}

\section{P. B. Cobbinah and M. Addaney (eds.),}

The Geography of Climate Change Adaptation in Urban Africa, https://doi.org/10.1007/978-3-030-04873-0

In the original version of the book, the corrections from author for Chapters 3,10,11,13, frontmatter and cover should be incorporated. The correction book has been updated with the changes.

The updated version of the book can be found at https://doi.org/10.1007/978-3-030-04873-0 https://doi.org/10.1007/978-3-030-04873-3 https://doi.org/10.1007/978-3-030-04873-10 https://doi.org/10.1007/978-3-030-04873-11 https://doi.org/10.1007/978-3-030-04873-13 